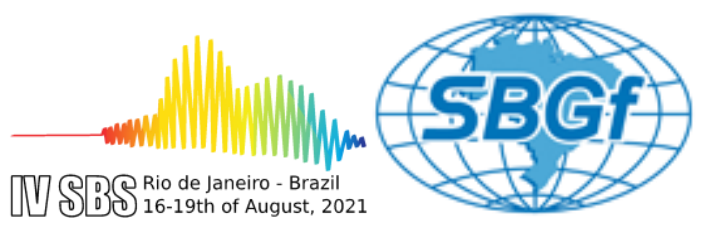

\title{
Infrasound Detections in the I09BR station
}

Brandow Lee Neri 1, Lucas Vieira Barros ${ }^{1}$, Arthur Macedo', Leticia Guedes', Mônica Giannoccaro Von Huelsen¹, 1Observatório Sismológico da Universidade de Brasília.

Copyright 2021, SBGf - Sociedade Brasileira de Geofísica

This paper was prepared for presentation during the $17^{\text {th }}$ International Congress of the Brazilian Geophysical Society held in Rio de Janeiro, Brazil, 16-19 August 2021.

Contents of this paper were reviewed by the Technical Committee of the $17^{\text {th }}$ International Congress of the Brazilian Geophysical Society and do not necessarily represent any position of the SBGf, its officers or members. Electronic reproduction or storage of any part of this paper for commercial purposes without the written consent of the Brazilian Geophysical Society is prohibited.

\begin{abstract}
Infrasound monitoring is one of the four technologies used by the International Monitoring System (IMS) to verify compliance with CTBT. Shallow atmospheric and underground nuclear explosions can generate infrasound waves that can be detected by infrasound networks. Of the 60 infrasound stations proposed by CTBT, one has been installed in Brazil since 2001. As the last nuclear tests were underground and on the Asian continent, the Brazilian infrasound station did not detect it. However, there are several other sources of infrasound signals detected by IS09 station. This work aims to present the results of the analysis of data, highlighting the main signal sources that the I09BR station has been detected over the years.
\end{abstract}

\section{Introduction}

The implementation of the International Monitoring System to verify compliance with the Comprehensive Nuclear-Test-Ban Treaty (CTBT) has generated rapid growth in interest in infrasound technology. The Treaty provides for a worldwide network of infrasound consisting of 60 permanent stations installed around the globe by various research organizations, in partnership with the Comprehensive Nuclear-Test-Ban Treaty Organization (CTBTO). $91 \%$ of these stations are already installed.

Infrasound is an inaudible sound by humans and its study is also called by the same name. As it is an acoustic disturbance, it is characterized by variations in air pressure, whose frequencies vary from $0.001 \mathrm{~Hz}$ to $20 \mathrm{~Hz}$ and, due to its high wavelengths, between $17 \mathrm{~m}$ and 30 $\mathrm{km}$, it can travel large distances in the atmosphere, as it suffers low attenuation (Gossard and Hooke 1975). The main function of the infrasound station is to measure atmospheric pressure fluctuations and convert them into a digital signal.

Infrasound stations were developed to detect atmospheric nuclear explosions. Each station consists of an array of spatially distributed sensors following a given geometry. One element of this arrangement is composed of a sensor (microbarometer), a noise reduction system, a photovoltaic power supply system, and a data transmission system using a secure communication system. Data from IMS stations are sent in near real-time to the IDC (
International Data Center), locate in Vienna - Austria (Christie \& Campus, 2009).

The Brazilian Infrasound station is located in Brasília, a subtropical region in the interior of Brazil. The four elements of the triangular arrangement of the I09BR are installed within the ecological reserve of the Brasilia National Park (PNB) about $20 \mathrm{~km}$ away from the Seismological Observatory of the University of Brasília (SIS - UnB) (Barros and Fontenele, 2002). The I09BR for safety and logistics reasons is in an appropriate location, as access to the environmental protection area is only allowed for authorized people, the PNB vegetation collaborates with noise levels, as it helps to filter out wind turbulence, and the station is close to the Central Data Reception and Recording Facility (Central Processing Facility) located at SIS - UnB.

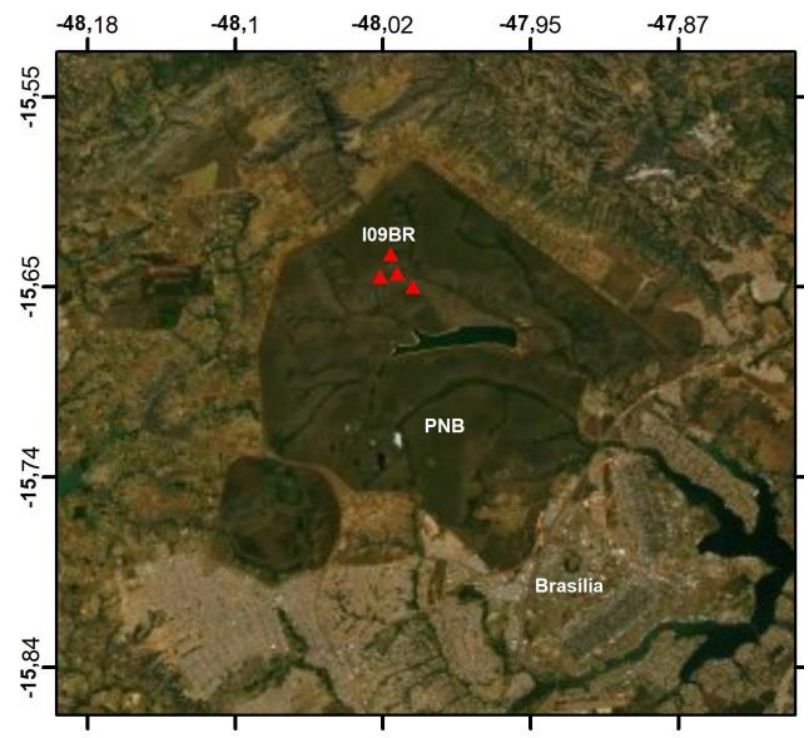

Figure 1: Location of the 109BR infrasund station arrangement.

The IMS network of infrasound stations was designed to reliably detect any atmospheric nuclear explosion with a power equivalent to or greater than one kiloton of TNT (1000 tons of TNT), anywhere in the world (Christie et al., 2001).

In addition to its use in CTBT verification, infrasound technology has application in scientific and social areas, like other natural and anthropogenic phenomena can also generate infrasound. For example large volcanic eruptions (Cotten et al., 1971; Fee et al., 2013; Jeffrey B Johnson et al., 2004; Jeffrey B Johnson \& Ripepe, 2011; Matoza R. et al., 2019; Jack W Reed, 1987); severe climates (Waxler \& Assink, 2019); detonations in mining companies (Bowman \& Bedard, 2010; Georges, 1973; Lin 
\& Langston, 2009); rocket launch and re-entry in the atmosphere (Cotten et al., 1971; Garces M. et al., 2004); supersonic aircraft (Liszka \& Waldemark, 1995), among others.

The infrasound stations of the International Monitoring Network almost always operate 24 hours a day 7 days a week without interruption. The I09BR records daily many infrasound signals from sources located around the station. In this study, 4 years (2015 to 2018) of data collected by the I09BR station were analyzed, showing the behavior of infrasound detections with the variation of the seasons. We also identified from the noisy background the main fixed sources that generate infrasound.

\section{Method}

Initially, the signal from the sensor (microbarometer) is converted by the digitizer into a digital signal that convert the analog signal in a digital signal. This data is then sent to IDC and can be requested by registered users from CTBT signatory countries. The first stage of data processing takes place individually, that is, the data from each station is processed individually. In this step, the infrasound detections Multi-Channel Progressive Correlation algorithm PMCC (Progressive Multichannel Correlation), Cansi (1995), and Cansi \& Klinger (1997), which is implemented in the DTK-PMCC and DTKGPMCC software, are produced. This signal detection technique was developed for application to seismic data and has proven to be efficient for extracting low amplitude signals contaminated by noise.

The processing set up to build the International Data Center PMCC Families uses 11 frequency bands between 0.07 and $4.0 \mathrm{~Hz}$, and in adjacent time windows covering the entire analysis period. The length of the processing window depends inversely on the frequency band. This ranges from 60 seconds for the lowest frequencies to 30 seconds for the highest frequency. This first processing stage produces elementary detections, called PMCC pixels, which satisfy the criteria of correlation and consistency (Figure 2 a). The next step is the grouping of individual detection pixels that have similar signal attributes in time, frequency, back azimuth, and horizontal velocity. Neighboring pixel groups constitute a PMCC family (Pichon et al., 2010) - Figure 2 b.
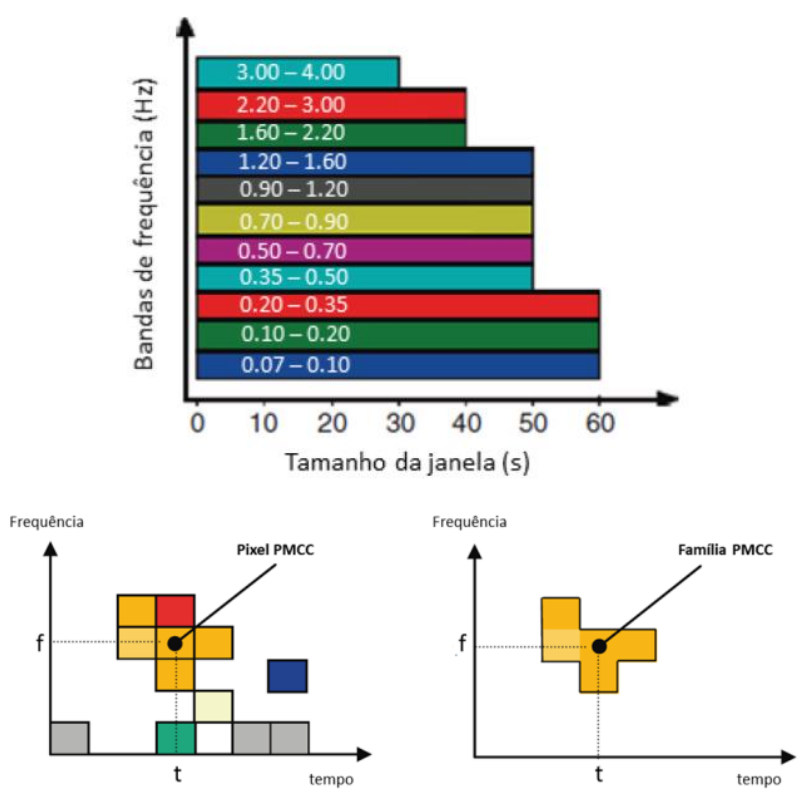

Figure 2: a) IDC configuration b) IDC configuration for PMCC processing, showing the duration of the processing time windows as a function of the frequency band. c) Formation of a PMCC family from pixels with similar characteristics (adapted from le Pichon et al., 2010).

With the infrasound detections of four years of data from the I09BR station, an evaluation of the behavior over time will be made using the DTK-DIVA software. Identify the orientation of the fixed sources that generate the infrared signal.

\section{Average weather conditions in Brasilia}

The report available at weatherspark.com shows Brasilia's characteristic weather conditions based on a statistical analysis of historical reports and reconstructions from January 1, 1980, to December 31, 2016. In Brasilia, there are two well-defined seasons, the dry season and the rainy season (Figure 3). The probability of rainy days in Brasilia varies widely throughout the year. The season with the highest rainfall lasts 6.2 months, from October 7th to April 14th, with more than $40 \%$ probability that on any given day it will rain. The dry season lasts 5.8 months, from April 14th to October 7th.

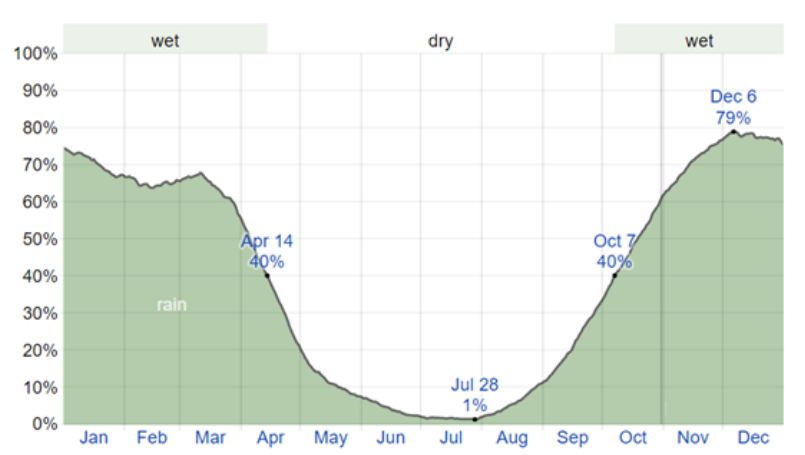

Figure 1: Precipitation probability in Brasilia (Weatherspark.com). 


\section{Results}

From the 4-year processing (2015 - 2018) using the PMCC algorithm, it is possible to identify a large number of infrasound detections. Unfortunately, for part of the year 2016, the station was inoperable, which is why on some dates it has not been given. Figure 4 shows the infrasound detection graph of the Brazilian station. The $x-$ axis represents time, the $y$-axis represents the azimuth from which the signals arrived, and the color scale represents frequency in hertz. In this Figure we can identify detections over the months with constant guidance. As is the case with azimuths around $180^{\circ}$ and $65^{\circ}$, which throughout all these years have highfrequency signals (red). Low-frequency signals (blue) are also registered over the months. The signal with an orientation of around $200^{\circ}$ to $250^{\circ}$ of low frequency occurs only during the dry season in Brasília. In Figure 4 it is also possible to see that during the rainy season the I09BR station detects more high-frequency signals compared to the dry season.
From the polar graphs of the number of detections separated by year (Figure 5), we can distinguish the groups as the main fixed sources of infrasound signal that the I09BR station detects. We also have a notion of the evolution of the amount of signal coming from each azimuth allowing us to have a notion of the source generating the signal.

The fixed infrasound signal sources closest to the I09BR station are the Votorantim Cimentos mining companies 15 $\mathrm{km}$ away $\left(60^{\circ}\right)$, and the urban center of the Federal District, with great influence from Brasília International Airport to the south. Figure 5 shows the considerable reduction over the years of detections arising from the explosions produced by the Votorantim mining companies. This is due to urban growth around the mining region, and pressure from residents to reduce the amount of blasting.

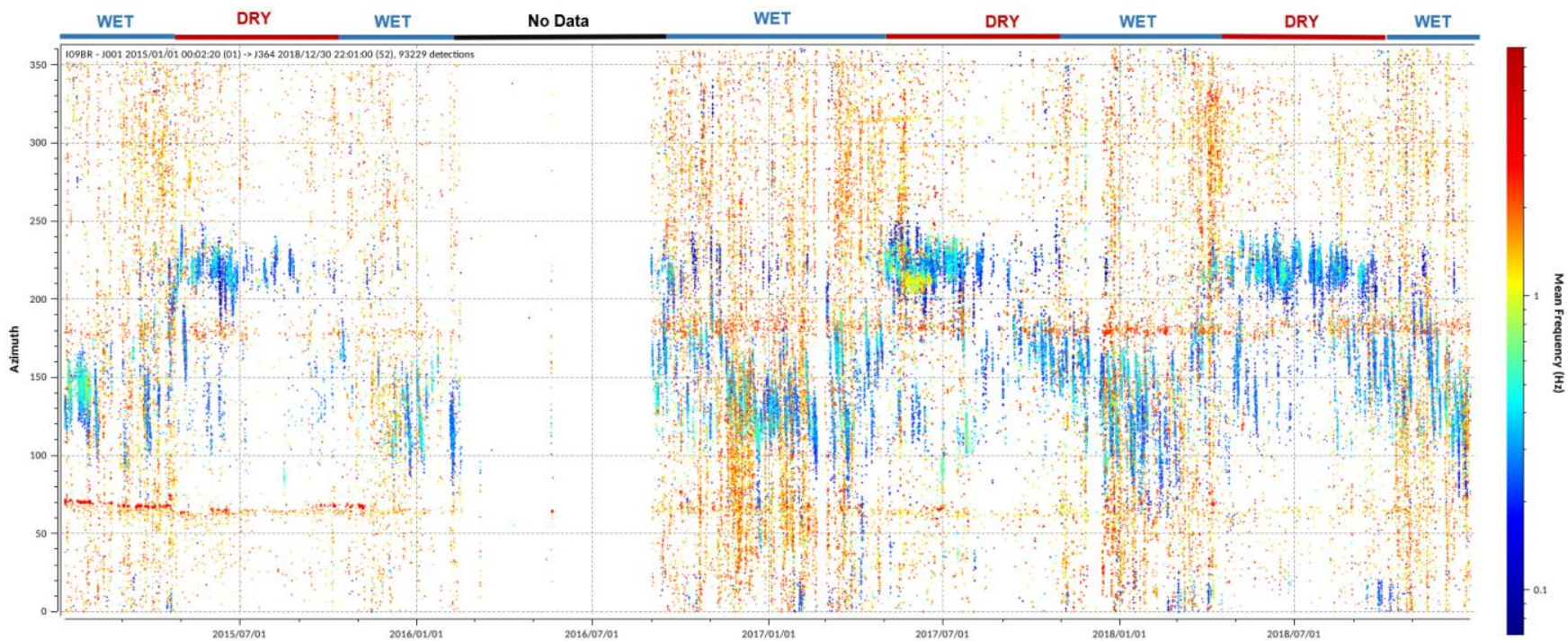

Figure 2: Graph of infrasonic detections by the I09BR station in the period from 2015 to 2018.
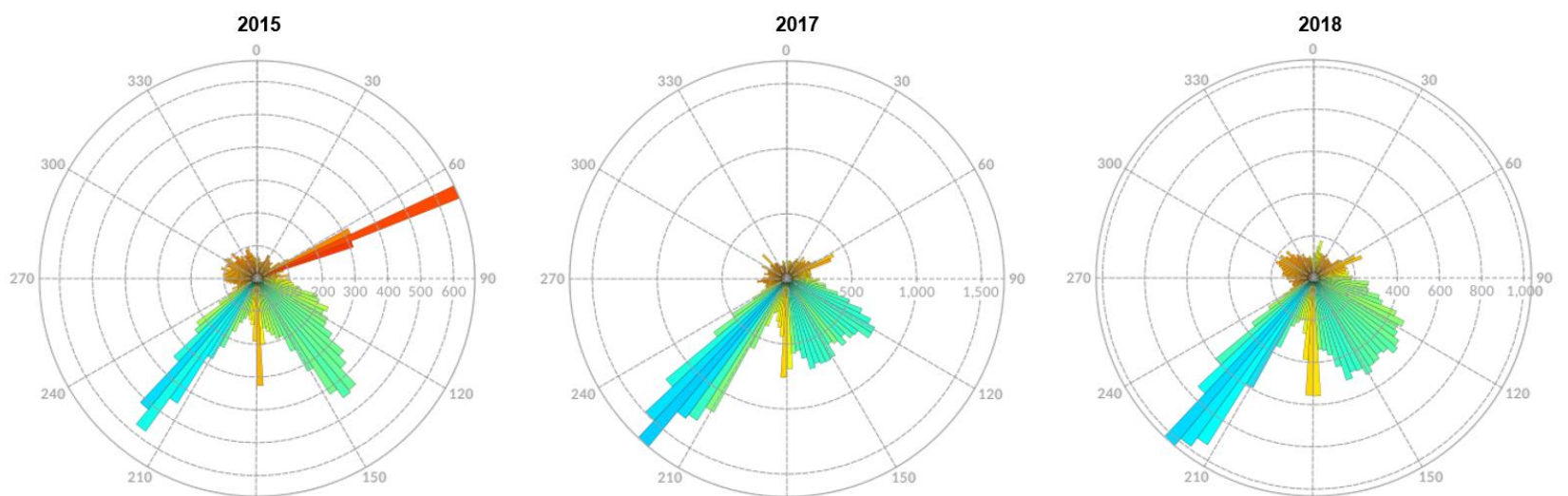

Figure 3: Polar graph of the number of infrasonic detections by the I09BR station. 
Part of the low-frequency signal from the $200^{\circ}$ to $250^{\circ}$ azimuth range are record only in the dry season.

A portion of the infrasound detections comes from the azimuthal range between $90^{\circ}$ and $170^{\circ}$, and has the same orientation as the Minas Gerais State that has the most mining companies in Brazil. Most of the signals acquired by the infrasound array are from sources close to the Earth's surface. Blasts in mining companies are typical examples of artificial sources that can be recorded, both in seismology and infrasound (Hagerty et al., 2002). Using the information from the UnB Seismological Observatory reports, it is not always possible to identify the PMCC families generated by the mining explosions. In 2017 for example, only $10 \%$ of the blasts were able to generate PMCC families (Figure 6), meeting the azimuth and probable arrival time requirements.

Figure 6 also shows other mining companies, to the south, southeast, and northwest, which also carry out blasts that generate infrasound signals that the 109BR station records, and are present in Figure 5.
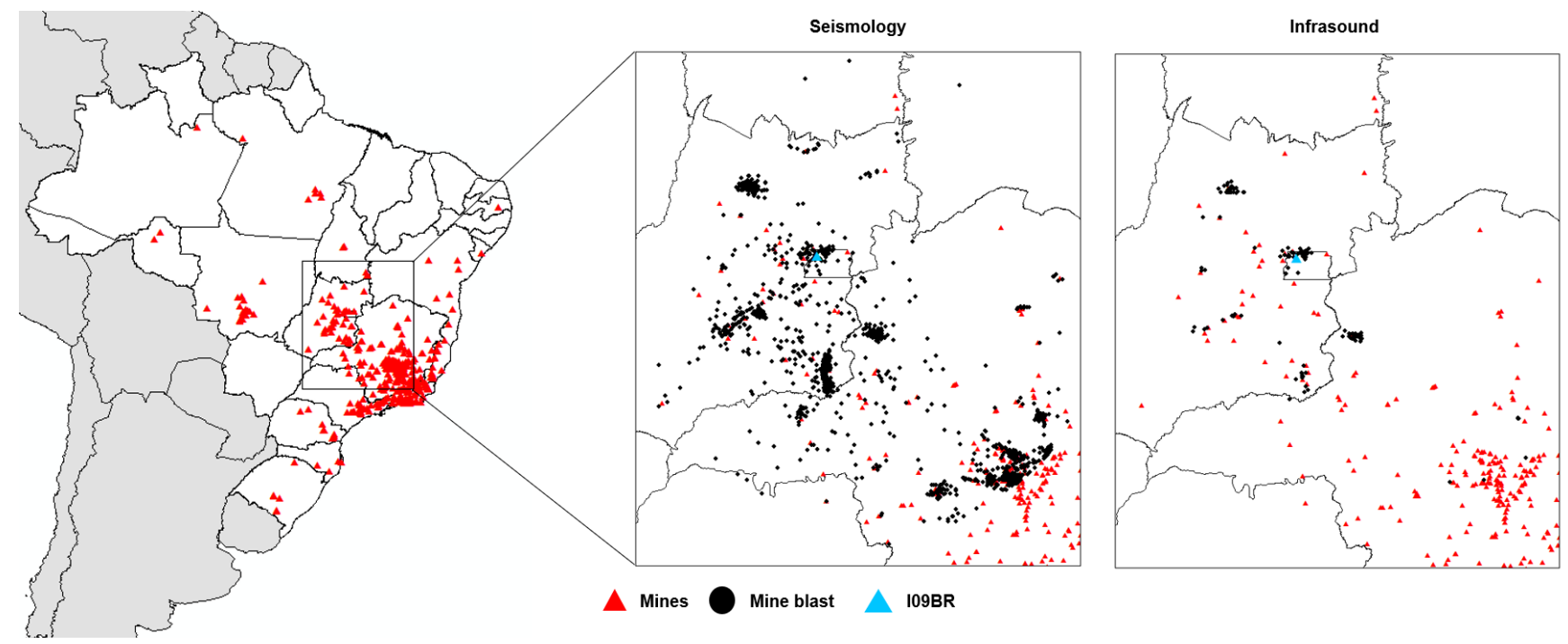

Figure 4: Relation of the number of blast detections in mining companies by the Brazilian seismographic network and by the I09BR station.

\section{Conclusions}

The Brasilia infrasound station, which belongs to the International Monitoring System, proved to be efficient in detecting signals of different natures. From the processing of a large period of data recorded by 109BR, we can identify the main fixed infrasound sources. The background noise of the infrasound station brings information that we can correlate with the weather conditions in which they are found, favoring or not the detection of a fixed source.

\section{Acknowledgments}

The authors would like to thank International Data Centre for the data and softwares used in this work. We would like to thank Furnas Centrais Elétricas S/A for the financial support. 


\section{References}

(Bowman \& Bedard, 2010; Y Cansi, 1995; Yves Cansi \& Klinger, 1997; Christie \& Campus, 2009; Cotten et al., 1971; Fee et al., 2013; Garces et al., 2004; Georges, 1973; Gossard \& Hooke, 1975; Hagerty et al., 2001; Jeffrey B Johnson et al., 2004; Jeffrey Bruce Johnson \& Ripepe, 2011; Lin \& Langston, 2009; Matoza et al., 2019; Pichon et al., 2010; Reed, 1987)Bowman, H., \& Bedard, A. (2010). Observations of Infrasound and Subsonic Disturbances Related to Severe Weather. Geophysical Journal of the Royal Astronomical Society, 26, 215-242. https://doi.org/10.1111/j.1365-246X.1971.tb03396.x

Cansi, Y. (1995). An automatic seismic event processing for detection and location: The P.M.C.C. Method. Geophysical Research Letters, 22(9), 1021-1024. https://doi.org/10.1029/95GL00468

Cansi, Yves, \& Klinger, Y. (1997). An automated data processing method for mini-arrays. News Lett, 11.

Christie, D. R., \& Campus, P. (2009). The IMS Infrasound Network: Design and Establishment of Infrasound Stations BT - Infrasound Monitoring for Atmospheric Studies (A. Le Pichon, E. Blanc, \& A. Hauchecorne (eds.); pp. 29-75). Springer Netherlands. https://doi.org/10.1007/978-1-40209508-5_2

Cotten, D. E., Donn, W. L., \& Oppenheim, A. (1971). On the Generation and Propagation of Shock Waves From Apollo Rockets at Orbital Altitudes. Geophysical Journal International, 26(1-4), 149159. https://doi.org/10.1111/j.1365246X.1971.tb03388.x

Fee, D., Matoza, R. S., Gee, K. L., Neilsen, T. B., \& Ogden, D. E. (2013). Infrasonic crackle and supersonic jet noise from the eruption of Nabro Volcano, Eritrea. Geophysical Research Letters, 40(16), 4199-4203. https://doi.org/https://doi.org/10.1002/grl.50827

Garces, M., Bass, H., Drop, D., Hetzer, C., Hedlin, M., Le Pichon, A., Lindquist, K., North, R., \& Olson, J. (2004). Forensic studies of infrasound from massive hypersonic sources. Eos, Transactions American Geophysical Union, 85(43), 433-441. https://doi.org/https://doi.org/10.1029/2004EO43000 2

Georges, T. M. (1973). Infrasound from convective storms: Examining the evidence. Reviews of Geophysics, 11(3), 571-594. https://doi.org/https://doi.org/10.1029/RG011i003p0 0571

Gossard, E. E., \& Hooke, W. H. (1975). Waves in the atmosphere: Atmospheric infrasound and gravity waves - Their generation and propagation. Atmospheric Science, 2. https://ui.adsabs.harvard.edu/abs/1975AtSc...2.... G
Hagerty, M., Kim, W.-Y., \& Martysevich, P. (2001). Infrasound Detection of Large Mining Blasts in Kazakstan. Pure and Applied Geophysics, 159. https://doi.org/10.1007/s00024-002-8673-3

Johnson, Jeffrey B, Aster, R. C., \& Kyle, P. R. (2004). Volcanic eruptions observed with infrasound. Geophysical Research Letters, 31(14). https://doi.org/https://doi.org/10.1029/2004GL02002 0

Johnson, Jeffrey Bruce, \& Ripepe, M. (2011). Volcano infrasound: A review. Journal of Volcanology and Geothermal Research, 206(3), 61-69. https://doi.org/https://doi.org/10.1016/j.jvolgeores.20 11.06 .006

Lin, T.-L., \& Langston, C. A. (2009). Thunder-induced ground motions: 2. Site characterization. Journal of Geophysical Research: Solid Earth, 114(B4). https://doi.org/https://doi.org/10.1029/2008JB00577 0

Matoza, R., Fee, D., Green, D., \& Mialle, P. (2019). Volcano Infrasound and the International Monitoring System BT - Infrasound Monitoring for Atmospheric Studies: Challenges in Middle Atmosphere Dynamics and Societal Benefits (A. Le Pichon, E. Blanc, \& A. Hauchecorne (eds.); pp. 1023-1077). Springer International Publishing. https://doi.org/10.1007/978-3-319-75140-5_33

Pichon, A. Le, Matoza, R., Brachet, N., \& Cansi, Y. (2010). RECENT ENHANCEMENTS OF THE PMCC INFRASOUND SIGNAL DETECTOR Frequency-dependent parameters Application to IMS data. 26, 5-8.

Reed, J. W. (1987). Air pressure waves from Mount St. Helens eruptions. Journal of Geophysical Research: Atmospheres, 92(D10), 11979-11992. https://doi.org/https://doi.org/10.1029/JD092iD10p1 1979 